\title{
Public Gardens: Fulfilling the University's Research Mission
}

\author{
Mary Hockenberry Meyer ${ }^{1,2}$, Stan Hokanson ${ }^{1}$, \\ Susan Galatowitsch ${ }^{1}$, and James Luby ${ }^{1}$
}

ADDITIONAL INDEX WORDs. botanic gardens, plant collections, arboreta

SUMMARY. Research at botanic gardens, from medieval times to the present day, has evolved to encompass a wide range of topics. The Minnesota Landscape Arboretum, part of the University of Minnesota, is an example of a diverse, successful research program within a public university garden setting. Collaboration, mission, organization, and publications are keys to a successful research program. Future research for public gardens, including putting collections to work for conservation, understanding global change, ecological genomics, restoration ecology, seed banking, and citizen science are collaborative ideas for all botanic gardens to consider.

Research can strengthen the botanic garden's role by providing public value while improving ties to the university.

U niversity public gardens offer a unique opportunity to showcase research in horticulture and plant science, as well as in diverse programs such as art, engineering, medicine, human nutrition, and information technology. Universities, especially land grant institutions, have an obligation to share public or botanic garden research and by doing so not only increase public knowledge, but strengthen the local university's contribution to the greater public good. The purpose of this article is to give a brief history of botanic garden research, show examples of Minnesota Landscape Arboretum (MLA) research projects, highlight keys to successful botanic garden research programs, and suggest future research projects that botanic gardens are uniquely positioned to accomplish. It is hoped that this article will further stimulate research at botanic gardens and thus continue to advance the value and importance of public gardens.

\section{Historic research at botanic gardens}

Medicinal use of plants was the original research of botanic gardens in the middle ages. With world exploration, plant collecting and cultivation of flora, especially from tropical climates, became very popular for botanic gardens in the 17th through 19th centuries. Royal Botanic Gardens, Kew, established a model that combined

\footnotetext{
${ }^{1}$ Department of Horticultural Science, University of Minnesota, St. Paul, MN 55108

${ }^{2}$ Corresponding author. E-mail: meyer023@umn.edu.
}

research, display, and education in 1842 as it became a public garden (Raven, 2006). Botanical gardens in Missouri and New York followed this pattern with major research divisions originally named botanical research institutes. More than half of the world's 2500 major botanic gardens have been created since 1950 (Crane et al., 2009) and the most recent survey (Watson et al., 1993) showed that only $40 \%$ listed research as a component of their work. As expected, university gardens $(74 \%)$ engage in research more often than non-university gardens (27\%) (Sacchi, 199l).

Comprehensive, labeled plant collections were the basis for the development of many botanic gardens (Watson et al., 1993); however, few gardens have specific research programs focused on their own living collections (Raven, 1986). Collections are the focus of nearly $50 \%$ of university garden's research (Sacchi, 1991). To be most effective, living plant collections should be specialized and have well-articulated research goals (Raven, 1986). Research using herbarium specimens often exceeds work using living collections at a botanic garden (Raven, 2006). Changes in the purpose and focus of botanic gardens are reflected in living collections that include "educational and horticultural display values which have surpassed any research use the collections may have once served" (Cook, 2006).

Traditional basic research especially suited for botanical gardens has included taxonomy, comparative morphology, phytochemical studies, biosystematics, evolutionary species differentiation, anatomy, embryology, physiology, genetic self-incompatibility, and plant pathology (Raven, 1986; Watson et al., 1993). Beginning in the 1970s, public or botanical gardens evolved to more beautiful display gardens with traditional collections modified to demonstrate various styles of landscape horticulture (DeVos, 1979). Horticultural and landscape use of new and novel plants from breeding programs has been a major focus of botanical garden research in the latter half of the 20th century.

While gardens of beauty are important, short- and long-term research projects add value and substance to the garden, and in times of difficult academic funding choices, it may be imperative for gardens to continue their university affiliation. Cook (2006) noted that "research is of vital importance to botanic gardens and confers great interest and legitimacy in the eyes of institutions supporters." Wagner (1972) stated that "a botanical garden with no research at all is little more than a kind of park; with research, such a garden develops a more profound significance to society." Steere (1969) felt that "no institution is privileged to call itself a botanic garden unless it is doing research of some kind and to some degree." Research has many benefits to the garden and society (Table 1).

More diverse research is now common at botanic gardens, including understanding climatic change by using herbarium specimens (Primack et al., 2004), evaluating informal learning (Eberbach and Crowley, 2004), understanding visitor preference for landscapes (Schroeder, 1993), restoration of native landscapes (Bader, 2001; Bohnen and Galatowitsch, 2005), pest resistance (Miller and Ware, 1994), plant conservation research (Havens et al., 2004), evolutionary diversification through new molecular tools (Cook, 2006), and improved nutrition with sustainable local crops (Sharrock, 2009).

\section{Research at the Minnesota Landscape Arboretum}

At the University of Minnesota, the Horticultural Research Center (HRC) was founded in 1908 as a fruit breeding farm. Through the years as 
the university grew, the HRC evolved to become a 230 -acre (93.1 ha) experiment station that was located adjacent to what developed into MLA, founded in 1958. MLA is part of the Department of Horticultural Science in the College of Food, Agriculture, and Natural Resources. In the mid 1980s, the HRC and MLA merged into one central administrative unit; however, the HRC is still one of the University of Minnesota's experiment stations (now called "research and outreach centers"). Having an experiment station or research and outreach center that is part of the public MLA makes it straightforward to have research conducted at this location. The research goals of MLA (Table 2) are part of the strategic plan and mission statement and are used to guide new and ongoing research projects.
OrNamental AND FRUIT BREEDING PROGRAMS. Over 101 years, the fruit breeding program at the HRC has released 106 fruit varieties, including 27 apple (Malus spp.), 22 plum (Prunus spp.), and 10 grape (Vitus spp.) varieties (Hansen and West, 2009). Fruit is sold at the Apple House on the HRC grounds in the summer and fall where people can purchase new releases as well as numbered selections from the breeding programs. The orchards are not open to the public unless there is an educational tour or field day.

The MLA's HRC ornamental breeding program has introduced 51 plants, including 13 azalea ( $R$ hododendron spp.), nine rose (Rosa spp.), 17 large and small trees, and one ornamental grass (Hansen and West, 2009). In 1957, A. Johnson

Table 1. Benefits of research at botanic gardens, especially living collections research. ${ }^{\mathrm{z}}$

\begin{tabular}{l}
\hline Institutional benefits: \\
\hline Improvement in collection care and management \\
Introduction of new materials \\
Enhancement of institution's reputation, especially through National America Plant \\
Collections Consortium \\
Enhancement of staff development \\
Collaboration with off-site researchers who rely on the living garden collection \\
Reference collection for taxonomic studies \\
Demonstration of phenotypic plasticity in long-lived collections \\
Planting according to taxonomic classification \\
Evolutionary history and functional biology study \\
Public or societal benefits:
\end{tabular}

Improved knowledge of plants: new and existing

Improved plants through breeding and selection

Environmentally responsible landscaping methods

Aid in understanding the importance of conservation and preservation of plant communities

Cultural information

${ }^{2}$ Adapted from Sacchi (1991) and Dosmann (2007).

Table 2. Research goals of the Minnesota Landscape Arboretum, University of Minnesota.

1 To examine the ways people perceive and are affected by the plants in their environment.

2 To maintain a coordinated research program dealing with acquisition, evaluation, breeding, culture, physiology, and use of plants.

3 To evaluate plant performance in response to the environments unique to urban and suburban areas and to breed and select plants that flourish in these environments.

4 To explore and develop sustainable cultural methods that can be applied in the urban and suburban landscape.

5 To make use of the arboretum's complex natural community to carry out ecological research.

crossed mollis azalea (Rhododendron $\times$ kosterianum) with roseshell azalea (Rhododendron prinophyllum), an act that heralded the start of the "Lights" deciduous azalea breeding program (Hokanson, 2010). In the 52 years since the first cross, thousands of additional crosses have been made, tens of thousands of seedlings have been evaluated, 634 selections have been made, and 13 "Lights" deciduous azalea cultivars have been released for use by the public (e.g., 'Candy Lights' and 'Lilac Lights'). The effort continues to this day with new breeding objectives and the prospect of a new generation of deciduous azaleas poised to become the next "Lights" azalea cultivars.

Many of these new ornamental plants are grown in public collections on the MLA grounds, where they can be evaluated by not only the research staff, but by the public and commercial industry. Early in MLA history, a list of all the native plants (312 species, 192 genera, and 63 families) on the property showed the diversity of native flora (Johnson et al., 1965). Research projects have involved evaluation of plants as well as production and propagation methods (Pellett, 1981). The ornamental grass collection was planted in 1987 and has over 100 different grasses. With over 20 years of field data, publications on the survival and growth of this collection have been important for the nursery trade in northern climates such as USDA Zone 4 (Meyer, 2004). Crosses and field evaluations are conducted on the plants in the MLA display gardens. Some collections have special interpretation and signage; for example, the ornamental grass collection is labeled to show cultivars growing side by side for field comparisons, and the rhododendron (Rhododendron spp.) collection has signage showing how plants are crossed using the most cold-hardy parents from around the world.

University of Minnesota Department of Horticultural Science faculty hire and manage research scientists at the HRC who work with MLA staff to manage research plots. This cooperative arrangement is critical to the success of research work at MLA. The supporting budget for staff comes from the faculty or project leader and from MLA. The proportion varies from $10 \%$ to $90 \%$, depending on the 
project. Some of the research projects are on property that is not open to the public, with only staff access; other projects are within the MLA public grounds.

ECOLOGICAL RESTORATION RESEARCH PROGRAM. Worldwide, botanic gardens and arboreta are playing a central role in advancing the science and practice of ecological restoration (Dixon and Sharrock, 2009). In many ways, botanic gardens and arboreta are "pre-adapted" for restoration leadership: they focus on difficult-tocultivate species, have the freedom to focus on applied science, have a wellestablished public interface, and can provide on-site opportunities to test and demonstrate restorations (Hopper et al., 2009). MLA has restored prairies, hardwood forest, and wetlands over the past 25 years.

The most ambitious restoration research project was Spring Peeper Meadow, a shallow marsh and meadow situated with an oak savanna, prairie, and woodland landscape. Just 15 years ago, many thought restoring high-quality examples of these ecosystems within an urban setting was unachievable. This was particularly true of sedge meadows, a once widespread kind of wetland, dominated by species [especially sedges (Carex spp.)] that were impossible to re-establish from seeds or plants. With support from the Minnesota Legislature and private donations, MLA purchased land in 1995 that had been drained and cultivated for over 70 years, was covered with invasive reed canary grass (Phalaris arundinacea), but had outstanding restoration potential. MLA scientists figured out how to remove invasive species and manage the hydrology to support the desired wetland ecosystems. This experience has become the standard for site preparation in the region. Most notably, MLA pioneered revegetation techniques for dozens of species that now can be reliably used in restorations statewide (Bohnen and Galatowitsch, 2005). With nearly 300 native wetland species, many consider Spring Peeper Meadow to be one of the highest quality wetlands in the Twin Cities metropolitan area. Restoration has expanded from the wetland into the upland savanna and forest in an attempt to restore an entire mosaic of the prairie-forest landscape.

Spring Peeper Meadow has also been an important education site while serving as a hub of research activity. Each year, more than 500 people visit the site on guided tours and many others enjoy the site on their own. Groups range from elementary schools, to seniors, and wetland professionals. A boardwalk and path system, together with signage that interprets how and why wetlands are restored, were designed so the public can get a close look at ecosystems being restored and know what new information is emerging from research while having a minimal impact on sensitive plant species and secretive nesting water birds and amphibians.

BIOREMEDIATION PARKING LOT. In 2002, additional parking at MLA was accommodated by building a new model bioremediation or a raingarden parking lot that holds over 150 cars. The U.S. Geological Survey monitored water flowing into and out of this raingarden for several years and the water quality data are being compiled by a water resources graduate student at the University of Minnesota to determine how effective this rain garden has been at improving water quality. Details are posted under an MLA sustainability link (Elliott and Meyer, 2009a).

Alternative TURFGRASS TRIALS. Lower maintenance lawns are of popular interest and two studies have been planted at MLA to evaluate new plants such as no-mow and ecology lawn mixes against standard coolseason grass mixtures. These trials were planted where the public could view the plants, compare them, and even vote on their favorite. Results showed that these new mixtures could be similar to conventional lawn mixes (Meyer and Pedersen, 1999). Current turfgrass evaluations involve native prairie grasses with minimal maintenance.

RUN OFF MODEL. The MLA built a runoff model parking lot showing five different levels of impervious surface to demonstrate how to improve water infiltration in parking and walkway areas. Interpretive signage shows the differences between these five areas. Plants and pervious paving allow from $10 \%$ to $100 \%$ of the water to infiltrate a specific area. Details are included in the sustainability section on the MLA website (Elliott and Meyer, $2009 \mathrm{~b}$ ). This area is often featured on tours and policy conferences as a demonstration site to study how paved areas minimize runoff and function over many years.

Horticultural therapy. One full-time horticultural therapist at MLA manages several on- and off-site therapeutic programs. Applied research from several years of teaching horticultural therapy to several thousand people resulted in the development of a curriculum for elders and youth to learn about each other and the world of plants (Larson and Meyer, 2006).

\section{Keys to successful research programs at a university public garden}

FACULTY AND STAFF COL LABORATION. If university faculty are using the public garden for research, collaboration between faculty and garden management and grounds staff is critical. At MLA, a research committee meets monthly to discuss the current work of any ongoing research projects. This research committee is composed of faculty and staff involved in any current research projects at MLA and HRC. Faculty are responsible for the hiring and supervision of research scientists that lead research projects. MLA staff supervise other workers and gardeners that work with research scientists to accomplish research goals. Graduate students, funded by faculty, work on research projects and do field labor, planting, and evaluation of projects. Student interns funded by faculty or MLA may also provide additional labor in the summer.

RESEARCH INTEGRATED IN MISSION. Research is one of the four parts of the MLA mission, and has a long successful history of which MLA and the university are very proud. MLA provides space where demonstration plots can be planted or projects can be established. Faculty ask MLA staff to be part of grants and MLA staff ask faculty to collaborate on grants that will fit for new projects at MLA. Faculty include salary for MLA staff and equipment items in grant budgets where allowed and appropriate. MLA management wants the public to see and learn from research projects at MLA. Gardeners and home owners can see and learn research findings on new plants, recommendations for lawn care, plants for difficult sites, etc. 
Organizational structure WITHIN THE UNIVERSITY. The MLA is part of the Department of Horticultural Science within the College of Food, Agriculture, and Natural Resources at a large land grant research university. Horticultural faculty are the most likely to do research, and to know MLA and its resources. MLA, being embedded within the university at a department level, allows the horticultural science faculty to be a part of MLA at the heart of the university. Departments are the functional units or engines of a university, and this allows the faculty to be involved in the growth and development of MLA.

University gardens are particularly suited for research due to their connection to faculty and students. More communication between the garden and academic faculty is always needed to keep everyone involved. Seeking donors who support academic programs for student interns or specific research projects or to maintain and enhance collections are ways to fund and sustain these important programs.

Publications. A concerted effort is needed to continually publish ongoing evaluation information about collections, new plants, and successful programs and educational events at botanic gardens. This applied research can be extremely important in showing what a garden is accomplishing. Long-term plant breeding programs do not always reflect on their historic work, but when viewed as a whole, it can be very impressive for internal and external use (Meyer, 2000). Increasingly, the details of new cultivars are first made public through plant patents as universities use intellectual property protection to capture additional value and encourage faster commercialization of new plants. Publishing information disseminates research findings to local gardeners, the horticulture industry, and to other regions of the country. Traditional publications are just one means of information dissemination (see Table 3 for additional examples of publicizing research work).

A virtual research tour online can convey the nature of research conducted at a public garden. If a library is part of the public garden, this is a natural place for information to be available to the public.

Table 3. Outreach efforts that publicize research at the Minnesota Landscape Arboretum, University of Minnesota.

\begin{tabular}{lc}
\hline Title & Description \\
\hline 150 Years of Hardy Plants & 16-page publication (Meyer, 2000) \\
Ornamental Grasses for Cold & 40-page publication (Meyer, 2004) \\
$\quad$ Climates & 36-page publication (Hansen and West, \\
Minnesota Hardy & 2009) \\
University of Minnesota Apples & Website (University of Minnesota, 2009a) \\
Posters and Publications, Apples & Website (University of Minnesota, 2009b) \\
University of Minnesota Grapes & Website (University of Minnesota, 2009c) \\
Posters of Grapes & Website (University of Minnesota, 2009d) \\
Hardy Plant Research Symposium & Website (Minnesota Landscape Arboretum, \\
Great Hall of Honor & 2008) \\
& 12-mo. exhibit of 53 posters showing 100 \\
\hline
\end{tabular}

\section{Future research at public gardens}

To undertake a new research program or renew an existing program, gardens might start by establishing a university-wide committee for garden engagement that would invite representatives from several departments, colleges, or institutes to meet and discuss research opportunities at their garden. Ideally, an endowed fund for research could be established to offer requests for proposals that would engage university faculty from various colleges or institutes. Various garden projects could be used as collaborative development and research initiatives. For example, the Department of Landscape Architecture might design a new entrance or welcome plaza; the Institute of Technology or engineering departments might develop a sustainable glasshouse of the future, and the Department of Horticultural Science may develop a native grass collection for breeding low-maintenance lawns.

The University of California at Davis Arboretum winds through the campus and has initiated a GATEways project with "a new mission: to inform visitors about the important ideas and complex issues UC Davis scientists and scholars are tackling..... working with campus and community partners to develop a multi-layered learning experience that will use teaching landscapes, public arts, exhibits, digital technologies, and interactions with students to engage and inspire visitors" (University of California, Davis, 2009).

Most public gardens have model gardens or demonstration plantings that are excellent for teaching and display, but do not necessarily involve research. These locations can, however, be an excellent place for applied research such as annual evaluations ofplant growth and development, winterhardiness, minimal maintenance, and drought tolerance. Further evaluation of native plants in the landscape, as well as propagation techniques, are needed today to expand our use and knowledge of the best regional plants. Determining what native plants are endangered within the state or region of a botanic garden can lead to preservation, propagation, and protection of regional endangered species. Learning the epicenter for diversity of native genera, for example, sedges in the upper midwestern U.S., could lead MLA to become a center for propagation and preservation of these native sedges.

Documenting self seeding of potentially invasive non-natives is another important area where public gardens should provide valuable information. These assessments can only be done on a regional or local level. Multiple-year evaluations can lead to publications and advance knowledge of plant hardiness and suitability of new plants for landscape plantings. Curatorial or research staff, along with gardeners, should summarize and publish their findings from annual plant evaluations, especially for areas where plant materials are limited due to rigorous climatic conditions. Student interns can be a source of labor for these projects, not only providing the human resources, but giving students a chance to make a significant contribution to horticultural science. 
Raven $(1986,2006)$ has continually advocated for a "sound database of plants in cultivation in botanical gardens throughout the world as an essential element for increasing the use of collections in research." With no knowledge of who has which species, little understanding of duplication in collections, and limited coordination of this information, how can botanical gardens make a serious contribution to research or to other human purposes? A global digital information system for plant collections is a critical goal, however, the quantity of primary data and complexity of numerous information technology systems must be overcome (Nic Lughadha and Miller, 2009). No doubt the lack of a global database for plant collections has slowed the visibility and impact of botanic garden research. Directors, especially of university gardens, question the role of research in their institution's mission as they face shrinking state and federal funding (Cook, 2006).

Crane et al. (2009) feels "at no other point in history have botanic gardens been so important......botanic gardens offer so much in terms of plant-based problem solving that is increasingly relevant to improving human welfare." Putting collections to work for conservation, understanding global change, ecological genomics, restoration ecology, seed banking, and citizen science are examples of new frontiers for botanical gardens of today (Crane et al., 2009).

Dosmann (2007) refers to a "crisis" in living collections in botanical gardens and natural history collections due to dwindling support and advocacy. He describes living plant collections as central in their role in supporting research. He further states that "if gardens fail to engage collections for research activity, they risk losing their long-standing societal commitment to collections-based science and relevance within the research community" (Dosmann, 2006). Gardens must be clear advocates for their collections and the research derived from them. Formal, on-site programs are not required for collections research. Off-site scientists can make great contributions through collaborative links. Curators and collections managers play an important role for off site new collaborations. Investment in data management systems is also required to increase collection value and to improve the ability to disseminate information to researchers who require it (Dosmann, 2007).

With reduced state income for many public universities, competition is fierce for existing resources. A university's public garden is a unique arena to show the benefits and value of a wide range of research. Academic institutions that have public gardens should be using them to showcase their research and to strengthen their university's overall public value.

\section{Literature cited}

Bader, B.J. 2001. Developing a species list for oak savanna/oak woodland restoration at the University of Wisconsin-Madison Arboretum. Ecol. Res. 19:242-245.

Bohnen, J. and S. Galatowitsch. 2005. Spring Peeper Meadow: Revegetation practices in a seasonal wetland restoration in Minnesota. Ecol. Res. 23:173-181.

Cook, R.E. 2006. Botanical collections as a resource for research. Public Garden 1:19-21.

Crane, P.R., S.D. Hopper, P.H. Raven, and D.W. Stevenson. 2009. Plant science research in botanic gardens. Trends Plant Sci. 14:575-642.

DeVos, F. 1979. The nature of present day collections. Amer. Assn. Bot. Garden Bul. 13:12-15.

Dixon, K. and S. Sharrock. 2009. Botanic gardens in the age of restoration. J. Bot. Gardens Conservation Intl. 6:3-5.

Dosmann, M.S. 2006. Research in the garden: Averting the collections crisis. Bot. Rev. 72:107-134.

Dosmann, M.S. 2007. The Arnold Arboretum's living collections: A repository for research. Arnoldia 65:30-39.

Eberbach, C. and K. Crowley. 2004. Learning research in public gardens. Public Garden 2:14-16.

Elliott, S. and M. Meyer. 2009a. University of Minnesota Landscape Arboretum parking lot rain garden. 27 Jan. 2010. <http://www.arboretum.umn.edu/User Files/File/RainGardenOutreach.pdf $>$.

Elliott, S. and M. Meyer. 2009b. University of Minnesota Landscape Arboretum run off model. 27 Jan. 2010. <http:// www.arboretum.umn.edu/UserFiles/ File/Runoff\%20Model\%20Outreach.pdf>.

Hansen, D. and A. West. 2009. Minnesota hardy. Univ. Minnesota, Minnesota Agr. Expt. Sta., St. Paul.
Havens, K., E.O. Guerrant, P. Vitt, and M. Maunder. 2004. Conservation research and public gardens. Public Garden 3:40-43.

Hokanson, S. 2010. Lights in the land of 10,000 lakes, p. 22-32. In: Royal Horticultural Society yearbook of camellias, magnolias and rhododendrons. Royal Horticultural Society, London.

Hopper, S., K. Hardwick, P. Fielder, L. Lee, B. Pavlik, and R. Hobbs. 2009. Globalizing restoration: A role for botanic gardens. 19th Conf. Soc. Ecol. Restoration Intl., Perth, Australia. p. 3. (Abstr.).

Johnson, A., G.J. Moore, and M. Smithberg. 1965. Native plants of the University of Minnesota Landscape Arboretum. Minnesota Landscape Arboretum, Chaska, $\mathrm{MN}$.

Larson, J.M. and M.H. Meyer. 2006. Generations gardening together: Sourcebook for intergenerational therapeutic horticulture. Haworth Press, Binghamton, NY.

Meyer, M.H. 2000. 150 years of hardy plants. Univ. Minnesota, Minnesota Agr. Expt. Sta., BU 7564.

Meyer, M.H. 2004. Ornamental grasses for cold climates. Univ. Minnesota Ext. Service, BU 6411.

Meyer, M.H. and B. Pedersen. 1999. Low maintenance alternative turfgrass trials. J. Turfgrass Mgt. 3:49-57.

Miller, F. and G. Ware. 1994. Preference for and suitability of selected elms: Ulmus spp. and their hybrids, or the elm leaf beetle, (Pyrrhalta luteola Coleoptera: Chrysomelidae). J. Environ. Hort. 12: 231-235.

Minnesota Landscape Arboretum. 2008. Hardy plant research symposium. $18 \mathrm{Dec}$. 2009. <www.arboretum.umn.edu/ hardyplantresearchsymposium.aspx $>$.

Nic Lughadha, E. and C. Miller. 2009. Accelerating global access to plant diversity information. Trends Plant Sci. 14: 622-628.

Pellett, H. 1981. Research activities during 1980, p. 36-39. In: 1980 Annual report. Minnesota Landscape Arboretum, Chaska, MN.

Primack, D., C. Imbres, R.B. Primack, A.J. Miller-Rushing, and P. DelTredici. 2004. Herbarium specimens demonstrate earlier flowering times in response to warming in Boston. Amer. J. Bot. 91: 1260-1264.

Raven, P.H. 1986. Research in botanical gardens, p. 32-52. In: M.J. Balick (ed.). Botanical gardens and arboreta: Future directions. New York Botanical Garden 
and Amer. Assn. Botanic Gardens Arboreta, Swarthmore, PA.

Raven, P.H. 2006. Research in botanical gardens. Public Garden 1:16-17.

Sacchi, C.S. 1991. The role and nature of research at botanic gardens. Public Garden 6:33-35.

Schroeder, H. 1993. Preference for and meaning of arboretum landscapes. Visitor Behavior 8:13-14.

Sharrock, S. 2009. Botanic gardens: Promoting the use of underutilized plants for improved nutrition and health. Acta Hort. 806:615-620.
Steere, W.C. 1969. Research as a function of a botanical garden. Longwood Prog. Seminars 1:43-47.

University of California. Davis. 2009. Arboretum GATEways project. 23 Nov. 2009. <http://arboretum.ucdavis.edu/ gateways_project.aspx $>$.

University of Minnesota. 2009a. Apples. 12 Dec. 2009. <http://www.apples.umn. edu $/>$.

University of Minnesota. 2009b. Posters and publications: Apples. 12 Dec. 2009. <http://www.apples.umn.edu/posters. html>.
University of Minnesota. 2009c. Cold hardy grapes. 12 Dec. 2009. <http:// www.grapes.umn.edu/>.

University of Minnesota. 2009d. Grape posters. 12 Dec. 2009. <http://www.grapes. umn.edu/order-form.pdf $>$.

Wagner, W.H. 1972. Botanical research at botanical gardens, p. 28-33. In: P.F. Rice (ed.). Proc. symposium on a national botanical garden system for Canada. Tech. Bul. Royal Bot. Gardens, Hamilton, $\mathrm{ON}$, Canada.

Watson, G., V. Heywood, and W. Crowley. 1993. North American botanic gardens. Hort. Rev. (Amer. Soc. Hort. Sci.) 15:1-62. 